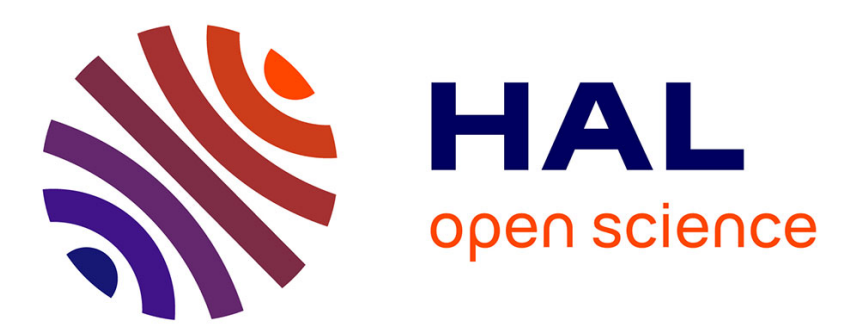

\title{
The critical importance of ionomers on the electrochemical activity of platinum and platinum-free catalysts for anion-exchange membrane fuel cells
}

Pietro G Santori, Abhishek N. Mondal, Dario R Dekel, Frederic Jaouen

\section{- To cite this version:}

Pietro G Santori, Abhishek N. Mondal, Dario R Dekel, Frederic Jaouen. The critical importance of ionomers on the electrochemical activity of platinum and platinum-free catalysts for anion-exchange membrane fuel cells. Sustainable Energy \& Fuels, 2020, 4 (7), pp.3300-3307. 10.1039/d0se00483a . hal-02886307

\section{HAL Id: hal-02886307 https://hal.science/hal-02886307}

Submitted on 1 Jul 2020

HAL is a multi-disciplinary open access archive for the deposit and dissemination of scientific research documents, whether they are published or not. The documents may come from teaching and research institutions in France or abroad, or from public or private research centers.
L'archive ouverte pluridisciplinaire $\mathbf{H A L}$, est destinée au dépôt et à la diffusion de documents scientifiques de niveau recherche, publiés ou non, émanant des établissements d'enseignement et de recherche français ou étrangers, des laboratoires publics ou privés. 
The critical importance of the ionomer on the electrochemical activity of platinum and platinum-free catalysts for anion-exchange membrane fuel cells

Pietro G. Santori, ${ }^{\mathrm{a}}$ Abhishek N. Mondal, ${ }^{\mathrm{b}}$ Dario R. Dekel, ${ }^{\mathrm{b}, \mathrm{c}}{ }^{*}$ and Frédéric Jaouen ${ }^{\mathrm{a}}{ }^{*}$

a ICGM, Univ. Montpellier, CNRS, ENSCM, Montpellier, France

${ }^{\mathrm{b}}$ The Wolfson Department of Chemical Engineering, Technion - Israel Institute of Technology, Haifa 3200003, Israel

${ }^{\mathrm{c}}$ The Nancy \& Stephan Grand Technion Energy Program (GTEP), Technion - Israel Institute of Technology, Haifa 3200003, Israel

* Corresponding authors: [DRD] dario@technion.ac.il; [FJ] frederic.jaouen@umontpellier.fr

pietro-giovanni.santori@etu.umontpellier.fr

abhishek07i@gmail.com

dario@technion.ac.il

frederic.jaouen@umontpellier.fr 


\begin{abstract}
Anion-exchange membrane fuel cells (AEMFCs) show remarkable and rapid progress in performance, significantly increasing the relevance for research on electrocatalysis of the oxygen reduction reaction (ORR) and hydrogen oxidation reaction (HOR) for this technology. Since much of the recent progress in AEMFC performance can be tied to the improved interface between anion-exchange ionomers (AEI) and catalysts, this topic deserves specific attention. This work reports the ORR and HOR activity measured in rotating disk electrodes for several ionomer-catalyst combinations, involving five different AEIs and Nafion ${ }^{\circledR}$ and four ORR and HOR catalysts selected from the best-in-class PGM-based and PGM-free catalytic materials. The results show little impact of the ionomers on the ORR and HOR activity of $\mathrm{Pt} / \mathrm{C}$ and $\mathrm{PtRu} / \mathrm{C}$ catalysts, respectively; however, the choice of the AEI has critical importance on the ORR activity of Fe-N-C and significant effect on the HOR activity of Pd$\mathrm{CeO}_{2} / \mathrm{C}$.
\end{abstract}

\title{
Keywords
}

Ionomer, catalyst, interface, anion-exchange ionomer, anion-exchange membrane fuel cell, alkaline electrolyte 


\section{Graphical abstract}

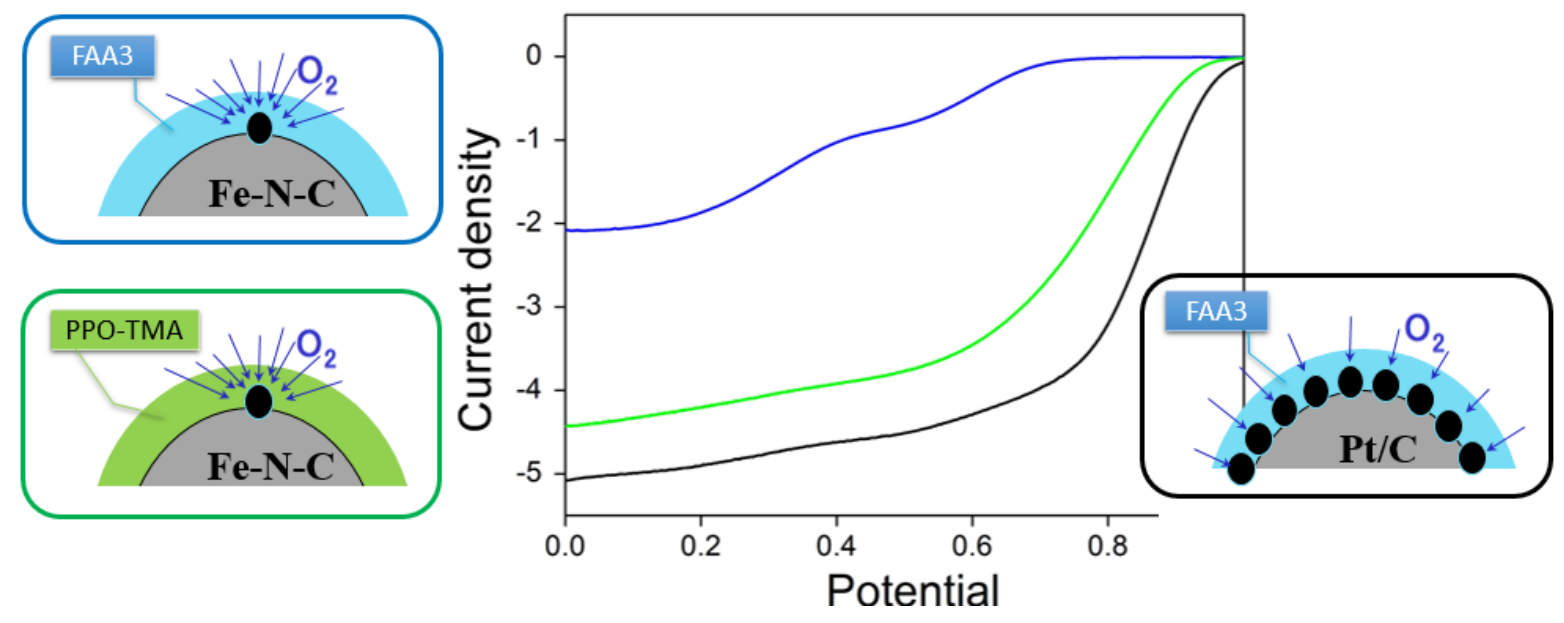




\section{Introduction}

The latest development of anion-exchange ionomers (AEIs) and membranes (AEMs) with high hydroxide conductivity have resulted in tremendous progress in the performance of AEM fuel cells $(\mathrm{AEMFCs})^{1-3}$. As a consequence, materials research for AEMFCs is a blooming multidisciplinary field that mainly involves polymer-, solid-state science, and electrocatalysis. Both AEMFCs and proton-exchange membrane fuel cell (PEMFC) can contribute to an overall greener energy production and conversion by efficiently converting green $\mathrm{H}_{2}$ (i.e. $\mathrm{H}_{2}$ produced from water and renewable energies) into electric power, releasing only heat and clean water in the process. Light-duty vehicles powered with green $\mathrm{H}_{2}$ and PEMFCs could, in particular, cut greenhouse gas emissions, compared to internal combustion engines fuelled with gasoline. ${ }^{4,5}$ Compared with the $c a 50$ year-long history of the competing PEMFC technology, the recently developed AEMFC technology holds the promise of comparable power performance and durability, ${ }^{1-3}$ while resorting to membrane and catalyst materials with significantly reduced environmental impact. Regarding membranes, they are identified as one of the crucial components for the power and durability performance of fuel cells. The now well-established membrane chemistry in PEMFC (Nafion ${ }^{\circledR}$ for example) leans on expensive perfluorinated polymer backbones functionalized with sulfonic acid groups. As a result, the production of such membranes involves the use of toxic gaseous fluorine or HF. In addition, their degradation during fuel cell operation releases toxic compounds into the environment. ${ }^{6,7}$ Regarding catalyst materials, the life cycle assessment of the current PEMFC technology is strongly negatively impacted by the use of high content of platinum group metals (PGMs) to catalyze both electrode reactions, in particular the oxygen reduction reaction (ORR) at the cathode. ${ }^{4,8}$ The acidic environment of PEMFC prevents the use of most non-PGM catalysts simply because of their thermodynamic instability in acidic medium. The intensely investigated class of $\mathrm{M}-\mathrm{N}-\mathrm{C}$ catalysts $(\mathrm{M}=\mathrm{Fe}$ or $\mathrm{Co})$ shows promising initial ORR 
activity and stability in acid medium (when not catalyzing the ORR) but suffers from low durability in operating PEMFCs. ${ }^{9}$ This, in particular, is due to the formation of reactive oxygen species and the occurrence of Fenton reactions between metal cations and $\mathrm{H}_{2} \mathrm{O}_{2}$ in acidic medium. ${ }^{10}$ In summary, the use of platinum in PEMFCs is a serious issue for the sustainability of this technology for mass production, ${ }^{11}$ and also leads to a strong environmental impact in the life cycle analysis. ${ }^{4,8,12}$

In contrast, AEMFCs lean on greener AEM chemistries that are free of fluorinated compounds, while their high equivalent $\mathrm{pH}$ environment allows a broad range of materials for catalyzing the reactions at the cathode and anode side, without resorting to rare and expensive PGMs. For this reason, catalysts research for AEMFCs is of increasing interest in the electrochemical energy community. For the ORR, while high activity and durability are presently reached with catalysts based on PGMs ${ }^{13-16}$, the current focus is to replace them with PGM-free catalysts $^{17-26}$ or even with metal-free carbon-based catalysts ${ }^{21,27,28}$. For the hydrogen oxidation reaction (HOR), sluggish kinetics of HOR in the alkaline medium seems very challenging even for PGM-based catalysts ${ }^{29-35}$. For the AEIs and AEMs the current focus of research is to increase their chemical stability under AEMFC operating conditions ${ }^{36-}$ 38

While separate development for each class of material is necessary, mutual interaction between catalytic and ionomeric materials at each electrode must be taken into account to achieve optimized AEMFC performance. However, catalyst-AEI interaction is an unexplored field, with only a very scarce number of studies having focused on the interaction effect between ORR and HOR electrocatalysts and AEI in the alkaline medium of AEMFCs. Jervis et al. showed that coupling $\mathrm{Pt} / \mathrm{C}$ with acidic proton-exchange ionomer underestimated its HOR activity in alkaline electrolyte ${ }^{39}$. The authors claimed that Nafion acts as an insulator of $\mathrm{OH}^{-}$, affecting hydroxide transport towards the catalytic surface and through the Nafion thin 
film. They emphasized the imperative need to couple catalysts with AEIs while evaluating HOR activity in alkaline medium. Kim et al. revealed that the adsorption of some AEI functional groups onto the surface of Pt and Pt-M bimetallic catalysts negatively impacted their HOR activity in alkaline electrolyte ${ }^{40}$, and in turn, the AEMFC performance ${ }^{41}$. The authors demonstrated that Pd-based HOR catalysts deactivated following adsorption and hydrogenation of phenyl group ${ }^{42}$, indicating that co-adsorption of cation-hydroxide-water can occur on the surface of PGM catalysts, limiting the hydrogen diffusion on their surface, and therefore affecting catalyst activity towards HOR in alkaline medium ${ }^{43}$. All the above studies focused on PGM-based catalysts for HOR. To the best of our knowledge, there are no studies on AEI-catalyst interactions either for ORR catalysis or for PGM-free materials.

In this study, we investigated the catalytic activity of different AEI-catalyst inks in alkaline electrolyte using the rotating disk electrode (RDE) method. The materials of this work comprise different AEIs, HOR and ORR catalysts, selected from the best-in-class Pt-based, low-PGM and PGM-free catalysts.

\section{Materials and Methods}

The ionomers and catalysts used in this study are summarized in Table 1 . To synthesize the polyphenylene oxide (PPO)-based AEIs, we prepared brominated PPO (Br-PPO, 25\% bromination degree) as reported elsewhere ${ }^{44}$. About $0.5 \mathrm{~g}$ Br-PPO was dissolved into $5 \mathrm{wt} \%$ N-Methyl-2-pyrrolidone solution in a $25 \mathrm{~mL}$ round bottom flask and functionalized with excess of trimethylamine (TMA), triethylamine (TEA), 1-methylpyrrolidine (MPy) or N,Ndimethylbenzylamine (DMBA). Once the reaction was completed, the polymer solution was cast and dried for $24 \mathrm{~h}$ into AEI films. Within experimental reproducibility of the synthesis, these four different AEIs have similar ion-exchange capacity (normalized per mass of PPO, i.e. excluding the slightly different mass due to the different chemistries of the side-chain comprising the functional groups), differing only in the chemistry of the functional group. ${ }^{44}$ 
The theoretical IEC for the four PPO-based ionomers named as PPO-TEA, PPO-TMA, PPODMBA an PPO-MPy are $1.73,1.86,1.63$ and $1.77 \mathrm{mmol} \cdot \mathrm{g}^{-1}$, respectively.

The Fe-N-C catalyst with atomically-dispersed Fe sites (labeled $\mathrm{Fe}_{0.5}-950$ ) was prepared as $\mathrm{in}^{45}$, with ORR alkaline activity and stability using Nafion ionomer for RDE studies, reported $\mathrm{in}^{46}$. The $\mathrm{Pd}-\mathrm{CeO}_{2} / \mathrm{C}$ catalyst was prepared as reported $\mathrm{in}^{1}$. We selected a loading of $10 \mathrm{wt} \%$ $\mathrm{Pd}$, as it was found to achieve the highest HOR activity ${ }^{1}$. Baseline inks were prepared by adding $54 \mu \mathrm{L}$ of either AEI (5 wt $\%$ in dimethylformamide) or Nafion, and $836 \mu \mathrm{L}$ of ethanol to $5 \mathrm{mg}$ catalyst, resulting in ionomer/catalyst mass ratio of 0.51 . For FAA3 (commercial AEI from Fumatech $\mathrm{GmbH}$ ) an additional ink formulation was also used, with half the amount of ionomer (named FAA3 halved).

The choice of the 0.51 ratio is derived from our previous study on the same $\mathrm{Fe}_{0.5}-950$ catalyst (> $95 \%$ carbon) in alkaline electrolyte using Nafion ionomer ${ }^{46}$ and also comparable to ionomer/carbon ratios of $0.42-0.62$ used by Omasta et al. for PtRu/C catalysts in combination with an AEI in optimized AEMFCs ${ }^{47}$. For consistency, with the PGM-based catalysts we used the same baseline ink formulation as for $\mathrm{Fe}_{0.5}-950$. With the halved FAA3/catalyst ratio, the ionomer-to-carbon ratio of the $\mathrm{Pt} / \mathrm{C}$ and $\mathrm{PtRu} / \mathrm{C}$ catalysts investigated in this study falls actually in the range employed by Omasta et al. in their AEMFC tests ${ }^{47}$. After sonicating the inks for $1 \mathrm{~h}, 7 \mu \mathrm{L}$ of it was applied onto glassy carbon tip (Pine Research) and dried overnight under vacuum at room temperature, to achieve working electrodes with $200 \mu \mathrm{g}_{\mathrm{cat}} \mathrm{cm}^{-2}$. It is important to note that all AEIs were in Br-form during ink preparation. The RDE studies were carried out in a three-electrode set-up with a reversible hydrogen electrode (RHE) reference and a graphite plate counter electrode. Cyclic-voltammetry (CV) was applied in $\mathrm{N}_{2}$-saturated electrolyte (SP-300, BioLogic Potentiostat). The ORR and HOR activities were measured in the potential range $0-1 \mathrm{~V}$ and $0-0.4 \mathrm{~V}$ vs. RHE, respectively. 
To investigate the extent of the exchange from bromide to hydroxide-form of the AEIs, the $\mathrm{Br}$ and $\mathrm{C}$ elemental contents in ORR active layers were measured before and after their immersion in $0.1 \mathrm{M} \mathrm{KOH}$ for $1 \mathrm{~h}$ by scanning electron microscopy (SEM) / energy-dispersive $\mathrm{X}$-ray spectroscopy (EDX). We prepared four inks following the procedure described above for $\mathrm{RDE}$ ink preparation, differing according to the ORR catalyst ( $\mathrm{Pt} / \mathrm{C}$ or $\left.\mathrm{Fe}_{0.5}-950\right)$ and the AEI (PPO-TEA or FAA3). To prepare thin films for SEM/EDX measurements, an aliquot of the dispersion was drop cast on a conductive carbon tape (cut with a $5 \mathrm{~mm}$ diameter) and attached to standard SEM pin stubs mounts. At least three areas of the samples were investigated for each case, and we report the averaged $\mathrm{Br}$ and $\mathrm{C}$ contents.

In addition, the electrochemical effect of bromide concentration in $0.1 \mathrm{M} \mathrm{KOH}$ on the ORR activity was investigated for the specific combination of $\mathrm{Fe}_{0.5}-950$ with PPO-TEA (at the baseline $\mathrm{AEI} /$ catalyst ratio) by adding $\mathrm{KBr}$ to the electrolyte to reach, in sequence, concentrations of $0.5,1,2,3,4$ and $5 \mathrm{mM} \mathrm{KBr}$.

\section{Results \& Discussion}

Figure 1 shows the ORR and HOR polarisation curves for all the catalysts, recorded for each ionomer with the baseline ink formulation, and additionally for FAA3 with a halved ionomer/catalyst ratio.

\subsection{Effect of ionomer for ORR}

We discuss ORR activity on the basis of Faradaic current density at $0.9 \mathrm{~V}$ vs. RHE as read from Figure 1. For Pt/C, the ORR activity is independent of the AEI (-1.6 to $-1.8 \mathrm{~mA} \mathrm{~cm}{ }^{-2}$ at $\left.0.9 \mathrm{~V}_{\mathrm{RHE}}\right)$ and similar to that obtained with Nafion $\left(-1.8 \mathrm{~mA} \mathrm{~cm} \mathrm{~cm}^{-2}\right.$ at $\left.0.9 \mathrm{~V}_{\mathrm{RHE}}\right)$. Only for FAA3 the activity is slightly lower (filled yellow circles, $-1.2 \mathrm{~mA} \mathrm{~cm}^{-2}$ at $0.9 \mathrm{~V}_{\mathrm{RHE}}$ ) but this effect disappears with halved FAA3/catalyst mass ratio (open yellow circles). This might be 
interpreted as excess FAA3 with the baseline ink formulation. A similar ORR activity for Pt/C with all AEIs is correlated with similar CVs (Fig. 2a). While activities at $0.9 \mathrm{~V}_{\mathrm{RHE}}$ are similar, the transition from the kinetically-controlled to the diffusion-limited region of polarisation curves is less sharp for Pt/C with baseline FAA3 content (filled yellow circles, Fig. 1a). Also, it is noted that the diffusion-limited current density $\left(\mathrm{J}_{\text {lim }}\right)$ is slightly lower for Pt/C with the synthesized PPO-based AEIs as compared to the case of Pt/C-Nafion, at baseline ionomer content. This may indicate either a less-selective ORR on Pt/C interfaced with such AEIs or a lower $\mathrm{O}_{2}$ permeability in PPO-based AEIs compared to Nafion. A decreased permeability could lead to a significant diffusion barrier through the AEI thin film covering catalytic particles. AEIs and AEMs are known to possess one order of magnitude lower $\mathrm{O}_{2}$ and $\mathrm{H}_{2}$ permeability than Nafion ${ }^{48}$.

More significant changes of the ORR activity with AEI is observed for $\mathrm{Fe}_{0.5}-950$, especially with FAA3 (Fig. 1b). While the ORR activity at $0.9 \mathrm{~V}_{\mathrm{RHE}}$ is similar for $\mathrm{Fe}_{0.5}-950$ interfaced with any of the synthesized AEIs and comparable to that obtained with the Nafion, in the range of -0.37 to $-0.47 \mathrm{~mA} \mathrm{~cm}{ }^{-2}$, no ORR activity is observed for $\mathrm{Fe}_{0.5}-950$ interfaced with FAA3 at baseline or halved FAA3/catalyst ratio (yellow or filled circles, Fig. 1b). The corresponding polarisation curves can, in fact, be assigned to the ORR activity of glassy carbon (dashed curve). This is correlated by the lack of signal in the CVs (yellow symbols, Fig. 2b). In contrast, the $\mathrm{CVs}$ of $\mathrm{Fe}_{0.5}-950$ coupled with any other AEI presently investigated are comparable, and comparable to that obtained for $\mathrm{Fe}_{0.5}-950$ with the Nafion (Fig. 2b). The strong effects of the ionomer shown in these results obtained with $\mathrm{Fe}_{0.5}-950$-FAA3 may be interpreted by (i) a film of FAA3 formed on top of glassy-carbon, thereby electrically insulating $\mathrm{Fe}_{0.5}-950$ from the current collector, or (ii) a film of FAA3 formed on the surface of all catalytic particles, electrically insulating each of them. Hypothesis (ii) seems, however, more likely to explain the results observed. We also note that for the other AEIs, the fine 
trends observed for $\mathrm{Fe}_{0.5}-950$ are similar to those observed for $\mathrm{Pt} / \mathrm{C}$, with a lower $\mathrm{J}_{\text {lim}}$-value reached with the AEIs compared to that observed with Nafion. The decrease of $J_{\lim }$ when switching from Nafion to AEI is more exacerbated here for $\mathrm{Fe}_{0.5}-950$ than for $\mathrm{Pt} / \mathrm{C}$. Also, the transition from the kinetically-controlled region to the diffusion-limited region of the polarisation curves for $\mathrm{Fe}_{0.5}-950$ is less sharp with PPO-based AEIs than with Nafion, possibly indicating an additional diffusion barrier due to the AEI thin-film, in line with the generally lower gas permeability of such AEIs compared to Nafion. This diffusion barrier would expectedly play an important role as the density of active sites decreases (from 60 to 2 wt\% metal from $\mathrm{Pt} / \mathrm{C}$ to $\mathrm{Fe}_{0.5}-950$ ), similar to what has been reported for Nafion-Pt/C, where decreased Pt content resulted in increased diffusion barrier ${ }^{49,50}$.

\subsection{Effect of ionomer for HOR}

Similar to the case for ORR on $\mathrm{Pt} / \mathrm{C}$, the HOR activity on $\mathrm{PtRu} / \mathrm{C}$ is invariable with the synthesized AEI, as can be seen from nearly superimposed curves in the range $0-2 \mathrm{~mA} \mathrm{~cm}{ }^{-2}$, and similar to that obtained with the Nafion (Fig. 1c). However, in the case of FAA3 at baseline content, the polarisation curve strongly deviates from the others already at $0.5 \mathrm{~mA}$ $\mathrm{cm}^{-2}$, and has an apparent $\mathrm{J}_{\lim }$-value that is 2.5 times lower than the theoretical one (filled yellow circles, Fig. 1c). This effect disappears when the FAA3 content is halved (open yellow circles), the apparent $\mathrm{J}_{\mathrm{lim}}$-value now even slightly exceeding that reached with PtRu/C coupled with Nafion (open yellow vs. filled black circles, Fig. 1c).

The identical HOR activity of PtRu/C obtained with the synthesized AEIs is correlated by similar CVs (Fig. 2c), nearly superimposed with the CV for PtRu/C with Nafion. In addition, 
the significantly lower $\mathbf{J}_{\text {lim }}$-value of the layer with FAA3 at baseline content is obviously correlated with a much supressed CV.

Similar to the case for ORR on $\mathrm{Pt} / \mathrm{C}$ and on $\mathrm{Fe}_{0.5}-950$, slightly lower $\mathrm{J}_{\text {lim }}$ values are observed for $\mathrm{HOR}$ on $\mathrm{PtRu} / \mathrm{C}$ with the AEIs than for PtRu/C with Nafion. Because the HOR can only be a two-electron reaction, this observation convincingly suggests that the AEI thin-film indeed results in an additional diffusion barrier. As for $\mathrm{Pt} / \mathrm{C}$, the effect is restricted for $\mathrm{PtRu} / \mathrm{C}$ due to the high density of active sites.

With all the synthesized AEIs and Nafion, the HOR polarisation curves on $\mathrm{Pd}-\mathrm{CeO}_{2} / \mathrm{C}$ show a linear shape up to $0.3 \mathrm{~V}$ vs. RHE (Fig. 1d), consistent with previously reported results for the same catalyst but with Nafion ${ }^{2}$. The apparent smaller HOR activity of $\mathrm{Pd}-\mathrm{CeO}_{2} / \mathrm{C}$ vs $\mathrm{PtRu} / \mathrm{C}$ is partly due to the lower PGM loading $\left(20 \mu \mathrm{g}_{\mathrm{Pd}} \mathrm{cm}^{-2}\right.$ and $\left.120 \mu \mathrm{g}_{\mathrm{PtRu}} \mathrm{cm}^{-2}\right)$. The intrinsic activity of $\mathrm{Pd}-\mathrm{CeO}_{2} / \mathrm{C}$ is therefore also high, and peak power density $>1 \mathrm{~W} \mathrm{~cm}^{-2}$ has been achieved with it in AEMFC ${ }^{2,51}$. The smaller slope of the polarisation curves observed on Pd$\mathrm{CeO}_{2} / \mathrm{C}$ with the synthesized AEIs in the $0-0.3 \mathrm{~V}$ region identifies a lower HOR activity and/or hydrogen access to the catalytic surface as for $\mathrm{Pd}-\mathrm{CeO}_{2} / \mathrm{C}$ coupled with the Nafion. With FAA3, no HOR activity is observed at baseline AEI content (filled yellow circles, Fig. 1d), while the HOR activity becomes comparable with that obtained with the other AEI when the FAA3 content is halved (open yellow circles, Fig. 1d). The HOR results are well correlated by the CVs seen in Fig. 2d. At baseline FAA3 content, there is no response in the $\mathrm{CV}$ (filled yellow circles), and this can be paralleled to the observation made for $\mathrm{Fe}_{0.5}-950$ at baseline FAA3 content. For the other cases, all CVs have a similar shape, differing only slightly in the overall signal intensity (Fig. 2d). It is stressed that the impact of switching from Nafion to the AEI on the electrocatalytic properties is stronger for $\mathrm{Pd}-\mathrm{CeO}_{2} / \mathrm{C}$ than $\mathrm{for} \mathrm{Pt} / \mathrm{C}$ and $\mathrm{PtRu} / \mathrm{C}$, and this ties with the lower density of active sites of $\mathrm{Pd}-\mathrm{CeO}_{2} / \mathrm{C}$ (only $10 \mathrm{wt} \%$ Pd). The negative impact when switching from Nafion to the AEI seems, therefore, to 
increase with a decreasing density of active sites in catalysts: $\mathrm{Pt} / \mathrm{C} \sim \mathrm{PtRu} / \mathrm{C}>\mathrm{Pd}-\mathrm{CeO}_{2} / \mathrm{C}>$ $\mathrm{Fe}_{0.5}-950$. This can be understood by the increased resistance for gas $\left(\mathrm{O}_{2}\right.$ or $\left.\mathrm{H}_{2}\right)$ permeation through an ionomer thin film towards the lower number of catalytic sites of these catalysts. On top of this, a secondary parameter playing a role might be the location of such active sites, with Fe-based sites being, at least in part, located in micropores in $\mathrm{Fe}_{0.5}-950^{45,46}$. Figure 3 schematically illustrates this. For a fixed electrode current density, the catalyst active sites have a higher ORR (or HOR) turnover frequency in an electrode with less number of active sites, leading in turn to a higher local flux of $\mathrm{O}_{2}\left(\mathrm{or}_{2}\right)$. The challenge of coupling AEI and catalysts to form active layers seems, therefore, to be more critical for the catalysts with low density of active sites ( $2 \mathrm{wt} \% \mathrm{Fe}$ and $10 \mathrm{wt} \% \mathrm{Pd}$ for $\mathrm{Fe}_{0.5}-950$ and $\mathrm{Pd}-\mathrm{CeO}_{2} / \mathrm{C}$, respectively) than for catalysts with high active sites density (60 wt\% metal for Pt/C and PtRu/C). This general observation suggests that an intrinsic issue with AEI might be their lower gas permeability compared to Nafion ${ }^{\circledR}$, due to different polymer backbone chemistries. While the observed differences between RDE results obtained with AEIs and Nafion® may be due to different gas permeability through the different ionomers, one important but hidden hypothesis when using AEI (here, initially in their brominated form) is that they quickly and fully exchange to their hydroxide form when immersed in $0.1 \mathrm{M} \mathrm{KOH}$ solution of the RDE tests. If this is not the case, this could negatively affect the permeability and $\mathrm{OH}^{-}$conductivity through the AEI thin-film covering the catalyst and, possibly, also affect the nature of the electrochemical double layer at the interface. In order to investigate this, we measured the bromide content in active layers comprising the ORR catalyst (namely $\mathrm{Pt} / \mathrm{C}$ or $\mathrm{Fe}_{0.5}-950$ ) with AEI (namely PPO-TEA or FAA3). The catalytic inks were prepared as RDE inks and drop cast on a conductive carbon tape (see Methods). The average bromide content of the layers before and after their immersion in $0.1 \mathrm{M} \mathrm{KOH}$ for $1 \mathrm{~h}$ is reported in Table 2. The first observation is that, even after $1 \mathrm{~h}$ in $0.1 \mathrm{M} \mathrm{KOH}$, all four active layers still contain a 
significant amount of bromide, between 10 and $30 \%$ relative to their initial $\mathrm{Br}$ content. This duration is comparable to the typical entire duration needed to acquire one set of RDE data according to the measurement protocol used in the present and other studies in the literature. Therefore, it can be assumed that the data presented in Table 2 are relevant to the RDE conditions. For the case of the PPO-TEA ionomer, the fraction of the AEI cationic sites remaining in bromide form in the thin-film layers may, therefore, be responsible for the slightly reduced diffusion-limited ORR current density observed for the Pt/C with PPO-TEA layer, as compared to that with Nafion (compare red curve and black circles in Figure 1a). In the case of $\mathrm{Pt} / \mathrm{C}$ ORR, the presence of a small number of cationic sites in bromide form in PPO-TEA that is in contact with the catalyst does, however, not lead to a decrease in the ORR activity at high electrochemical potential (compare red curve and black circles in Figure 1a). A similar discussion is valid for the ORR results obtained for Pt/C with FAA3 at baseline AEI/catalyst content (filled yellow circles in Figure 1a). Noteworthy, since the Br-content in the Pt/C - FAA3 and Pt/C - PPO-TEA films after immersion in $\mathrm{KOH}$ are comparable, around 22-24\% (last column in Table 2), one can conclude that FAA3 does not retain more bromide compared to that PPO-TEA does. This seems to imply that the lower diffusion-limited current densities reached with Pt/C - FAA3 vs. Pt/C - PPO-TEA must be assigned to an intrinsic lower permeability of FAA3 compared to the PPO-based AEIs.

The same observations and discussion are valid for the ORR results obtained with $\mathrm{Fe}_{0.5}-950$ combined either with PPO-TEA or with Nafion. The ORR activity is the same at high electrochemical potential with Nafion or PPO-TEA (the latter with a fraction of cationic sites in bromide form) while the diffusion-limited current density is slightly reduced in the case of PPO-TEA compared to Nafion (Figure $1 b$ ). This effect is assigned to a lower $\mathrm{O}_{2}$ permeability of the PPO-TEA thin film than Nafion thin film, either intrinsic to the PPO-TEA chemistry and/or due to the residual presence of bromide and therefore its incomplete exchange to 
hydroxide form of the PPO-TEA. While the permeability of such AEI as a function of the nature of the counter-anion has, to the best of our knowledge, not yet been investigated in the literature, one can expect a much lower gas permeability through AEIs in (bi)carbonate- and halide-form than in hydroxide-form, due to the significantly lower water uptakes these ionomers exhibit in the first, as compared to the latter forms ${ }^{52-54}$. The residual presence of bromide in the PPO-TEA AEI (and probably in the other PPO-based AEIs investigated here as well), may also explain the lower diffusion-limited current densities observed on the HOR polarisation curves obtained for $\mathrm{PtRu} / \mathrm{C}$ and $\mathrm{Pd} / \mathrm{CeO}_{2} / \mathrm{C}$ with any of the PPO-based AEIs, as compared to those obtained with Nafion (Figure 1c-d). Further studies will be necessary to unveil whether this effect is intrinsic to the lower permeability of PPO-based AEIs versus Nafion, or if this effect is solely due to the incomplete exchange to hydroxide-form of these AEIs. The discussion of the electrochemical results observed with FAA3 is more complex, since FAA3 often results in reduced CVs in $\mathrm{N}_{2}$-saturated electrolyte, implying a fraction of the catalytic particles are not electrochemically accessible (either not accessible by the electrolyte or by the electrons). The residual content of bromide in FAA3 cannot alone explain the reduced electrochemical capacitance, which in the case of $\mathrm{Fe}_{0.5}-950$ is dramatic. When FAA3 does not impact the capacitance however (e.g. with $\mathrm{Pt} / \mathrm{C})$, trends are similar as with the PPO-based AEIs.

To investigate in a controlled way how a mix of $\mathrm{Br}^{-}$and $\mathrm{OH}^{-}$anions in a catalytic thin-film impacts the kinetic and diffusion regions of a polarisation curve measured in RDE setup, we selected $\mathrm{Fe}_{0.5}-950$ and PPO-TEA materials and investigated the effect of $\mathrm{Br}^{-}$concentration in the electrolyte on the ORR polarisation curves of $\mathrm{Fe}_{0.5}-950$ / PPO-TEA film. The results show that both the kinetics and diffusion-limited current density decrease with increasing $\mathrm{Br}^{-}$ concentration from 0 to $5 \mathrm{mM}$ (Figure 3). Even a small concentration of $0.5-1.0 \mathrm{mM} \mathrm{KBr}$ results in a measurable decrease of the diffusion-limited current density of $0.3-0.6 \mathrm{~mA} \mathrm{~cm}^{-2}$. 
This simulates well the lower ORR diffusion-limited current densities observed when using PPO-based AEIs compared to Nafion (Figure 1a-b). At even higher $\mathrm{KBr}$ concentrations, the ORR activity of $\mathrm{Fe}_{0.5}-950$ starts decreasing. Overall, the results on the bromide residual content of the AEI show that specific protocols must be developed and adopted in the electrocatalysis research for RDE investigations with AEIs, so that the ionomers are completely exchanged to their hydroxide-form in order to access the intrinsic ORR and HOR activities of the catalyst materials.

\section{Conclusions}

In this study, we investigated the catalytic activity of different AEI-catalyst inks in alkaline electrolyte using the RDE method. The materials included different ionomers (Nafion, FAA3, and four PPO-based AEIs functionalized with different functional groups) and ORR and HOR catalysts $\left(\mathrm{Pt} / \mathrm{C}, \mathrm{Fe}_{0.5}-950 ; \mathrm{PtRu} / \mathrm{C}\right.$ and $\left.\mathrm{Pd}-\mathrm{CeO}_{2} / \mathrm{C}\right)$. Pt/C and $\mathrm{PtRu} / \mathrm{C}$ lead to high $\mathrm{ORR}$ and HOR activities, respectively, when coupled with any of the five AEIs. Compared to the coupling with Nafion, the activities are comparable but lower diffusion-limited current densities are observed for both ORR and HOR situations. This may be assigned to a lower gas permeability through AEIs compared to Nafion ${ }^{\circledR}$. Coupling $\mathrm{Fe}_{0.5}-950$ catalyst and AEIs was found more challenging, leading to a complete loss of ORR activity with FAA3, and to high activity with the four synthesized AEIs. In the latter case, the diffusion-limited current density was however also lower than that reached with Nafion. Regarding $\mathrm{HOR}$ on $\mathrm{Pd}-\mathrm{CeO}_{2} / \mathrm{C}$, all AEIs lead to comparable activity at low overpotential of 0-0.1 V, but significantly lower than the HOR activity observed with Nafion ${ }^{\circledR}$. This difference expanded at higher current density (higher potential). The results can be explained by a decreased permeability (mathematical product of concentration and diffusion coefficient) to $\mathrm{O}_{2}$ and $\mathrm{H}_{2}$ gases of the PPO-based AEIs compared to Nafion, due to the different polymer backbone chemistry and/or due to the incomplete exchange from bromide form to hydroxide-form of the AEIs. Catalysts with low 
site density would expectedly exacerbate the effect of lower permeability of the AEIs due to enhanced reactant consumption per active site, at a given geometric current density. This effect has been schemed in Figure 4. This may play a critical role in AEMFCs, where the current densities are orders of magnitude higher than those in RDE tests. Overall, this study shows the fundamental and practical importance of ionomer-catalyst interfaces for different classes of catalysts, with a dramatic impact on apparent activity. Improved fundamental understanding of how ionomers interact at the microscale with different classes of catalysts and different types of active sites (atomically dispersed metal-sites or metal-free sites vs. metallic or metal oxide particles in particular) is needed for the rational design of membraneelectrode assemblies and rational choices of catalyst and catalyst-compatible ionomers. The results also show the importance of establishing protocols for a complete counter-anion exchange of AEIs to their final required hydroxide-form not only for RDE measurements but also for AEMFC testing. Overall, the results give directions for the implementation in AEMFC of PGM-free and PGM-lean catalysts with novel AEI that are free of fluorine, important aspects to reduce the environmental impact of the polymer-electrolyte fuel cell technology.

\section{Acknowledgments}

This work was supported by the French-Israeli Joint Research Project (PRC 2019-2021; MOST and CNRS) [PRC2347]; by the European Union's Horizon 2020 research and innovation programme under grant agreement CREATE [721065]; by the Israel Science Foundation (ISF) [1481/17]; and by the Fuel Choice Initiative within the framework of "Israel National Research Center for Electrochemical Propulsion (INREP)".

\section{References}


H. A. Miller, F. Vizza, M. Marelli, A. Zadick, L. Dubau, M. Chatenet, S. Geiger, S. Cherevko, H. Doan, R. K. Pavlicek, S. Mukerjee and D. R. Dekel, Nano Energy, 2017, 33, 293-305. T. J. Omasta, X. Peng, H. A. Miller, F. Vizza, L. Wang, J. R. Varcoe, D. R. Dekel and W. E. Mustain, J. Electrochem. Soc., 2018, 165, J3039-J3044.

D. R. Dekel, J. Power Sources, 2018, 375, 158-169.

M. Miotti, J. Hofer and C. Bauer, Int. J. Life Cycle Assess., 2017, 22, 94-110.

F. T. Wagner, B. Lakshmanan and M. F. Mathias, J. Phys. Chem. Lett., 2010, 1, 2204-2219.

C. Chen, G. Levitin, D. W. Hess and T. F. Fuller, J. Power Sources, 2007, 169, 288-295.

M. Zatoń, J. Rozière and D. J. Jones, Sustain. Energy Fuels, 2017, 1, 409-438.

D. A. Notter, K. Kouravelou, T. Karachalios, M. K. Daletou and N. T. Haberland, Energy Environ. Sci., 2015, 8, 1969-1985.

M. Shao, Q. Chang, J.-P. Dodelet and R. Chenitz, Chem. Rev., 2016, 116, 3594-3657.

C. H. Choi, H.-K. Lim, M. W. Chung, G. Chon, N. R. Sahraie, A. Altin, M.-T. Sougrati, L. Stievano, H. S. Oh and E. S. Park, Energy Environ. Sci., 2018, 11, 3176-3182.

Y. Sun, M. Delucchi and J. Ogden, Int. J. Hydrogen Energy, 2011, 36, 11116-11127.

A. Simons and C. Bauer, Appl. Energy, 2015, 157, 884-896.

T. J. Omasta, L. Wang, X. Peng, C. A. Lewis, J. R. Varcoe and W. E. Mustain, J. Power Sources, 2018, 375, 205-213.

L. Wang, E. Magliocca, E. L. Cunningham, W. E. Mustain, S. D. Poynton, R. Escudero-Cid, M. M. Nasef, J. Ponce-González, R. Bance-Souahli, R. C. T. Slade, D. K. Whelligan and J. R. Varcoe, Green Chem., 2017, 19, 831-843.

L. Wang, M. Bellini, H. A. Miller and J. R. Varcoe, J. Mater. Chem. A, 2018, 6, 15404-15412.

Y. Wang, G. Wang, G. Li, B. Huang, J. Pan, Q. Liu, J. Han, L. Xiao, J. Lu and L. Zhuang, Energy Environ. Sci., 2015, 8, 177-181.

X. Peng, V. Kashyap, B. Ng, S. Kurungot, L. Wang, J. R. Varcoe and W. E. Mustain, Catalysts, 2019, 9, $1-12$.

H. Ren, Y. Wang, Y. Yang, X. Tang, Y. Peng, H. Peng, L. Xiao, J. Lu, H. D. Abruña and L. Zhuang, ACS Catal., 2017, 7, 6485-6492.

X. Peng, T. J. Omasta, E. Magliocca, L. Wang, J. R. Varcoe and W. E. Mustain, Angew. Chemie, 2019, 131, 1058-1063. 

Sources, 2018, 375, 233-243. ChemElectroChem, 2018, 5, 1827-1836.

N. Ralbag, M. Mann-Lahav, E. S. Davydova, U. Ash, R. Galed, M. Handl, R. Hiesgen, E. Magliocca, W. Mustain, J. He, P. Cong, A. M. Beale, G. S. Grader, D. Avnir and D. R. Dekel, Matter, 2019, 1, 959975.

Reio Praats; Maike Käärik; Arvo Kikas; Vambola Kisand; Jaan Aruväli; Päärn Paiste; Maido Merisalu; Ave Sarapuu; Jaan Leis; Väino Sammelselg; John C. Douglin; Dario R. Dekel; Kaido Tammeveski., J. solid state Electrochem.

V. M. Truong, J. R. Tolchard, J. Svendby, M. Manikandan, H. A. Miller, S. Sunde, H. Yang, D. R.Dekel and A. O. Barnett, accepted, Energies, 2019.

Y. Lu, L. Wang, K. Preuß, M. Qiao, M. M. Titirici, J. Varcoe and Q. Cai, J. Power Sources, 2017, 372, 82-90.

M. P. Kumar, M. M. Raju, A. Arunchander, S. Selvaraj, G. Kalita, T. N. Narayanan, A. K. Sahu and D. K. Pattanayak, J. Electrochem. Soc., 2016, 163, F848-F855.

E. S. Davydova, S. Mukerjee, F. Jaouen and D. R. Dekel, ACS Catal., 2018, 8, 6665-6690.

D. Strmcnik, M. Uchimura, C. Wang, R. Subbaraman, N. Danilovic, D. Van Der Vliet, A. P. Paulikas, V. R. Stamenkovic and N. M. Markovic, Nat. Chem., 2013, 5, 300-306.

D. R. Dekel, Curr. Opin. Electrochem., 2018, 12, 182-188.

E. S. Davydova, J. Zaffran, K. Dhaka, M. C. Toroker and D. R. Dekel, Catalysts, 2018, 8, 1-19.

A. Roy, M. R. Talarposhti, S. J. Normile, I. V. Zenyuk, V. De Andrade, K. Artyushkova, A. Serov and P. Atanassov, Sustain. Energy Fuels, 2018, 2, 2268-2275.

H. Yu, E. S. Davydova, U. Ash, H. A. Miller, L. Bonville, D. R. Dekel and R. Maric, Nano Energy, 2019, 57, 820-826.

N. Ralbag, E. S. Davydova, M. Mann-Lahav, P. Cong, J. He, A. M. Beale, G. S. Grader, D. Avnir, and D. R. Dekel, submitted, J. Electrochem. Soc.2019.

J. Fan, S. Willdorf-Cohen, E. M. Schibli, Z. Paula, W. Li, T. J. G. Skalski, A. T. Sergeenko, A. Hohenadel, B. J. Frisken, E. Magliocca, W. E. Mustain, C. E. Diesendruck, D. R. Dekel and S. Holdcroft, Nat. Commun., , DOI:10.1038/s41467-019-10292-z. 
R. Jervis, N. Mansor, A. J. Sobrido, S. Jones, C. Gibbs, T. P. Neville, J. Millichamp, P. R. Shearing and D. J. L. Brett, J. Electrochem. Soc., 2017, 164, F1551-F1555.

I. Matanovic, H. T. Chung and Y. S. Kim, J. Phys. Chem. Lett., 2017, 8, 4918-4924.

S. Maurya, C. H. Fujimoto, M. R. Hibbs, C. Narvaez Villarrubia and Y. S. Kim, Chem. Mater., 2018, 30, 2188-2192.

S. Maurya, J. H. Dumont, C. N. Villarrubia, I. Matanovic, D. Li, Y. S. Kim, S. Noh, J. Han, C. Bae, H. A. Miller, C. H. Fujimoto and D. R. Dekel, ACS Catal., 2018, 8, 9429-9439.

D. Li, H. T. Chung, S. Maurya, I. Matanovic and Y. S. Kim, Curr. Opin. Electrochem., 2018, 12, 189195.

S. Willdorf-Cohen, A. N. Mondal, D. R. Dekel and C. E. Diesendruck, J. Mater. Chem. A, 2018, 6, 22234-22239.

A. Zitolo, V. Goellner, V. Armel, M. T. Sougrati, T. Mineva, L. Stievano, E. Fonda and F. Jaouen, Nat. Mater., 2015, 14, 937-942.

P. G. Santori, F. D. Speck, J. Li, A. Zitolo, Q. Jia, S. Mukerjee, S. Cherevko and F. Jaouen, J. Electrochem. Soc., 2019, 166, F3311-F3320.

T. J. Omasta, A. M. Park, J. M. Lamanna, Y. Zhang, X. Peng, L. Wang, D. L. Jacobson, J. R. Varcoe, D. S. Hussey, B. S. Pivovar and W. E. Mustain, Energy Environ. Sci., 2018, 11, 551-558.

H. Ono, J. Miyake, S. Shimada, M. Uchida and K. Miyatake, J. Mater. Chem. A, 2015, 3, 21779-21788.

S. Jomori, N. Nonoyama and T. Yoshida, J. Power Sources, 2012, 215, 18-27.

S. Kinoshita, T. Tanuma, K. Yamada, S. Hommura, A. Watakabe, S. Saito and T. Shimohira, in ECS Transactions, Electrochemical Society Inc., 2014, vol. 64, pp. 371-375.

M. Bellini, M. V. Pagliaro, A. Lenarda, P. Fornasiero, M. Marelli, C. Evangelisti, M. Innocenti, Q. Jia, S. Mukerjee, J. Jankovic, L. Wang, J. R. Varcoe, C. B. Krishnamurthy, I. Grinberg, E. Davydova, D. R. Dekel, H. A. Miller and F. Vizza, ACS Appl. Energy Mater., 2019, 2, 4999-5008.

A. Amel, N. Gavish, L. Zhu, D. R. Dekel, M. A. Hickner and Y. Ein-Eli, J. Memb. Sci., 2016, 514, 125134.

53 Y. Zheng, U. Ash, R. P. Pandey, A. G. Ozioko, J. Ponce-González, M. Handl, T. Weissbach, J. R. Varcoe, S. Holdcroft, M. W. Liberatore, R. Hiesgen and D. R. Dekel, Macromolecules, 2018, 51, 3264 3278. 


\section{Tables and Figures}

Table 1. Key chemistry and composition of ionomeric and catalytic materials and inks

\begin{tabular}{|c|c|c|}
\hline Ionomer label & Cationic group & Polymer backbone \\
\hline Nafion & -- & PTFE-like \\
\hline FAA3 & Quaternary ammonium & Not available \\
\hline PPO-TEA & & PPO \\
\hline PPO-TMA & & PPO \\
\hline PPO-DMBA & & $\mathrm{PPO}$ \\
\hline PPO-MPy & & PPO \\
\hline Catalyst label & Composition, wt $\%$ & AEI/catalyst wt. ratio ${ }^{1}$ \\
\hline $\mathrm{Pt} / \mathrm{C}$ & $60 \% \mathrm{Pt} / 40 \% \mathrm{C}$ & 0.51 \\
\hline $\mathrm{PtRu} / \mathrm{C}$ & $40 \% \mathrm{Pt} / 20 \% \mathrm{Ru} / 40 \% \mathrm{C}$ & 0.51 \\
\hline $\mathrm{Fe}_{0.5^{-}} 950$ & $2 \% \mathrm{Fe} / 4 \% \mathrm{~N} / 94 \% \mathrm{C}$ & 0.51 \\
\hline
\end{tabular}


${ }^{1}$ For baseline ink formulation. For FAA3, a secondary ink formulation with halved FAA3/catalyst ratio was studied for all catalysts. The catalyst mass comprises all elements, not only metals. 
Table 2. Average content of carbon and bromide in active layers prepared with ORR catalysts ( $\mathrm{Pt} / \mathrm{C}$ or $\left.\mathrm{Fe}_{0.5^{-}}-950\right)$ and AEIs in bromide form (PPO-TEA or FAA3). The $\mathrm{C}$ and $\mathrm{Br}$ contents were measured by SEM/EDX before and after immersion in $0.1 \mathrm{M} \mathrm{KOH}$. The last column presents the relative $\mathrm{Br}$ content, normalized for each layer by the $\mathrm{Br}$ content measured before immersion in $\mathrm{KOH}$.

\begin{tabular}{|l|l|l|l|l|}
\hline $\begin{array}{l}\text { Catalyst - AEI } \\
\text { combination }\end{array}$ & $\begin{array}{l}\text { Before or after } \\
\text { immersion in } \mathrm{KOH}\end{array}$ & $\mathrm{Wt} \%$ carbon & $\mathrm{Wt} \%$ bromide & $\begin{array}{l}\text { Relative \% } \\
\text { bromide }\end{array}$ \\
\hline \multirow{2}{*}{$\mathrm{Pt} / \mathrm{C}$ - PPO-TEA } & before & 61.9 & 2.1 & 100 \\
\cline { 2 - 5 } & after & 56.4 & 0.5 & 23.8 \\
\hline \multirow{2}{*}{$\mathrm{Pt} / \mathrm{C}-\mathrm{FAA3}$} & before & 52.5 & 6.0 & 100 \\
\cline { 2 - 5 } & after & 52.4 & 1.3 & 21.7 \\
\hline $\mathrm{Fe}_{0.5}-950-$ PPO-TEA & before & 83.8 & 2.8 & 100 \\
\cline { 2 - 5 } & after & 85.8 & 0.3 & 10.7 \\
\hline $\mathrm{Fe}_{0.5}-950-\mathrm{FAA3}$ & before & 83.1 & 4.5 & 100 \\
\cline { 2 - 5 } & after & 87.4 & 1.3 & 28.9 \\
\hline
\end{tabular}



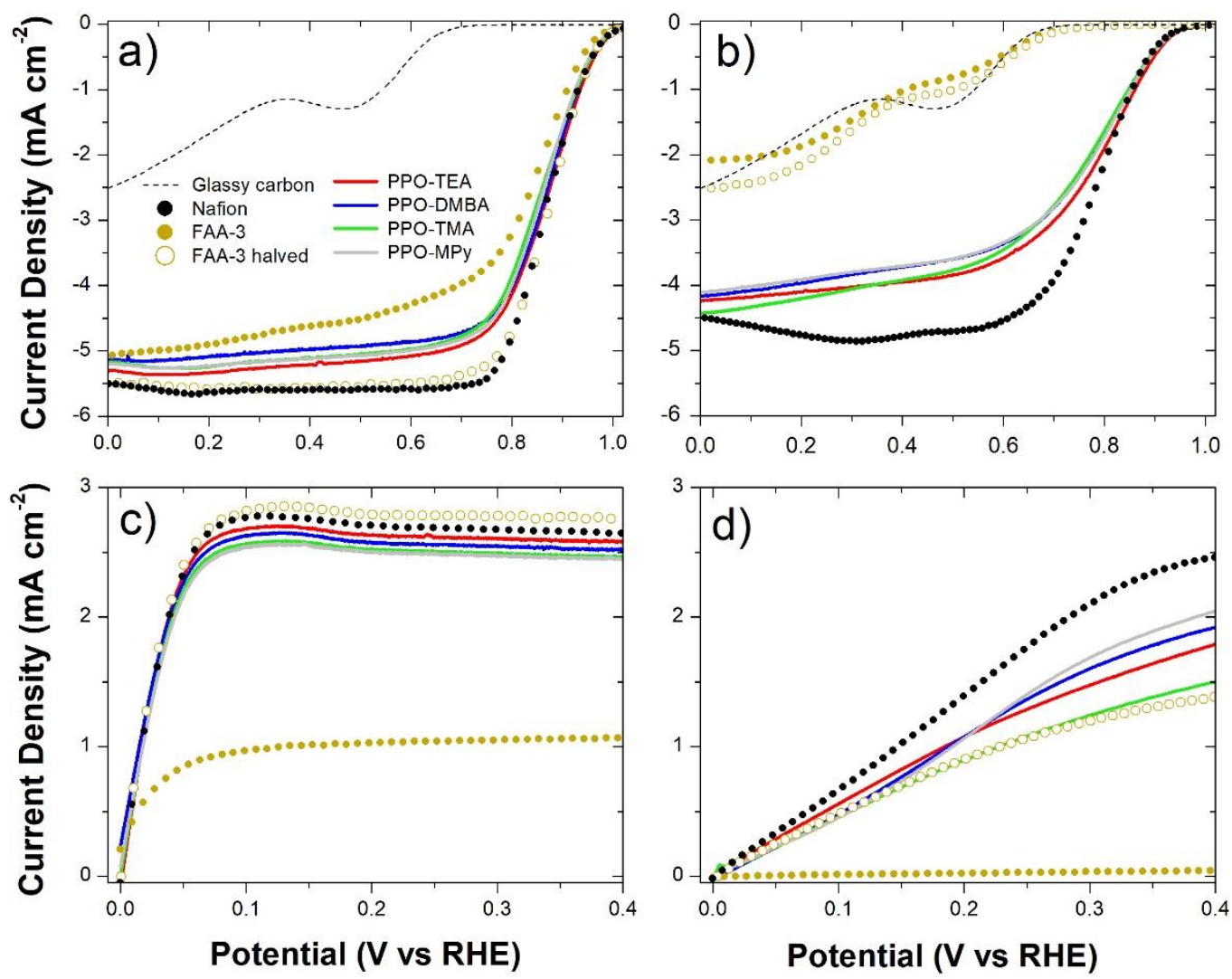

Figure 1. Polarisation curves for ORR on a) $\mathrm{Pt} / \mathrm{C}$ and b) $\mathrm{Fe}_{0.5^{-}}-950$; and $\mathrm{HOR}$ on c) $\mathrm{PtRu} / \mathrm{C}$ and d) $\mathrm{Pd}-\mathrm{CeO}_{2} /$ C. $0.1 \mathrm{M} \mathrm{KOH}$ electrolyte saturated with $\mathrm{O}_{2}$ or $\mathrm{H}_{2}, 1600 \mathrm{rpm}$, scan rate $1 \mathrm{mV}$ $\mathrm{s}^{-1}$, catalyst loading $200 \mu \mathrm{g} \mathrm{cm}{ }^{-2}$. 

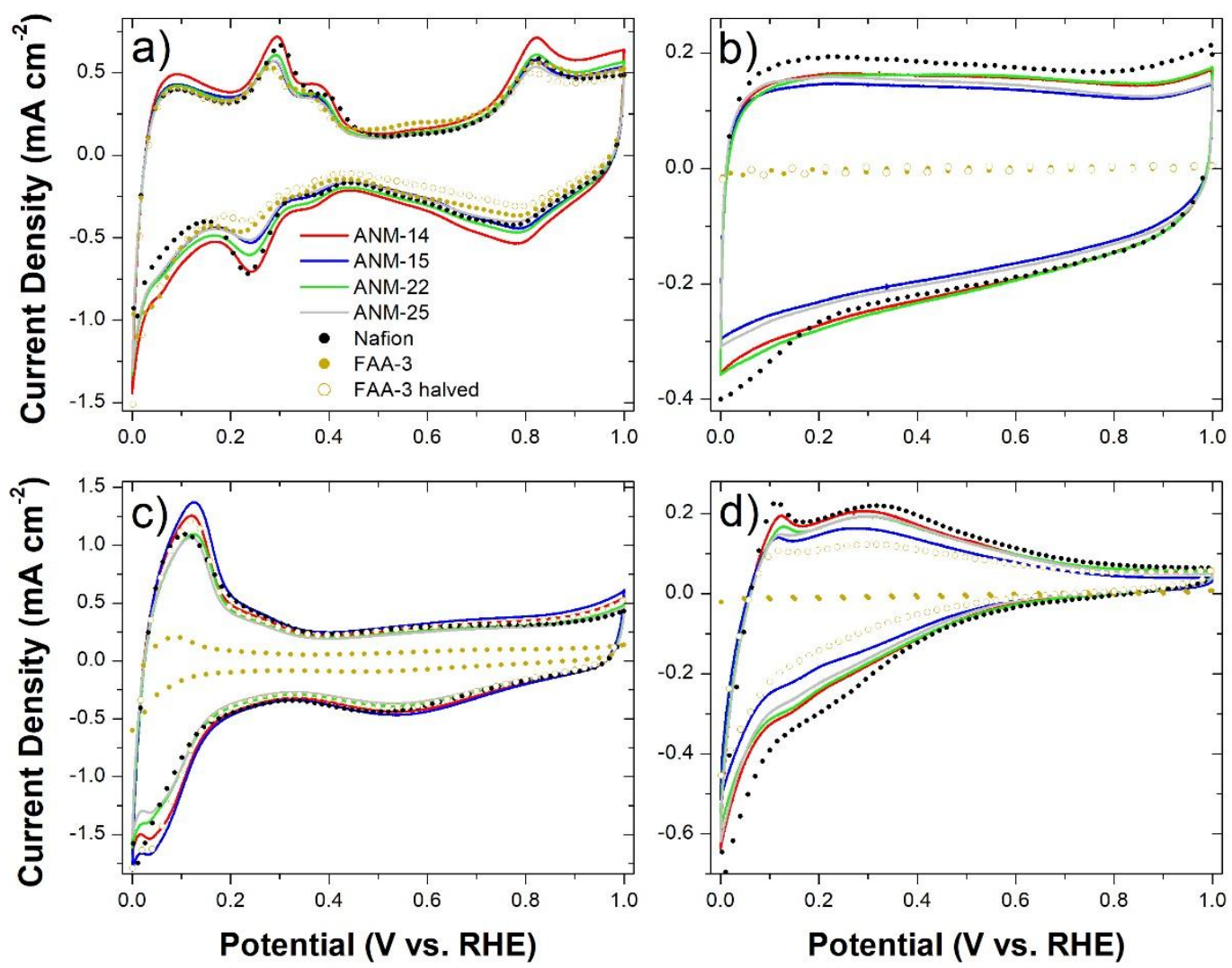

Figure 2. $\mathrm{CV}$ s for a) $\mathrm{Pt} / \mathrm{C}$, b) $\mathrm{Fe}_{0.5}-950$, c) $\mathrm{PtRu} / \mathrm{C}$ and d) $\mathrm{Pd}-\mathrm{CeO}_{2} / \mathrm{C} .0 .1 \mathrm{M} \mathrm{KOH}$ electrolyte saturated with $\mathrm{N}_{2}$, scan rate $10 \mathrm{mV} \mathrm{s}^{-1}$, catalyst loading $200 \mu \mathrm{g} \mathrm{cm}^{-2}$. 

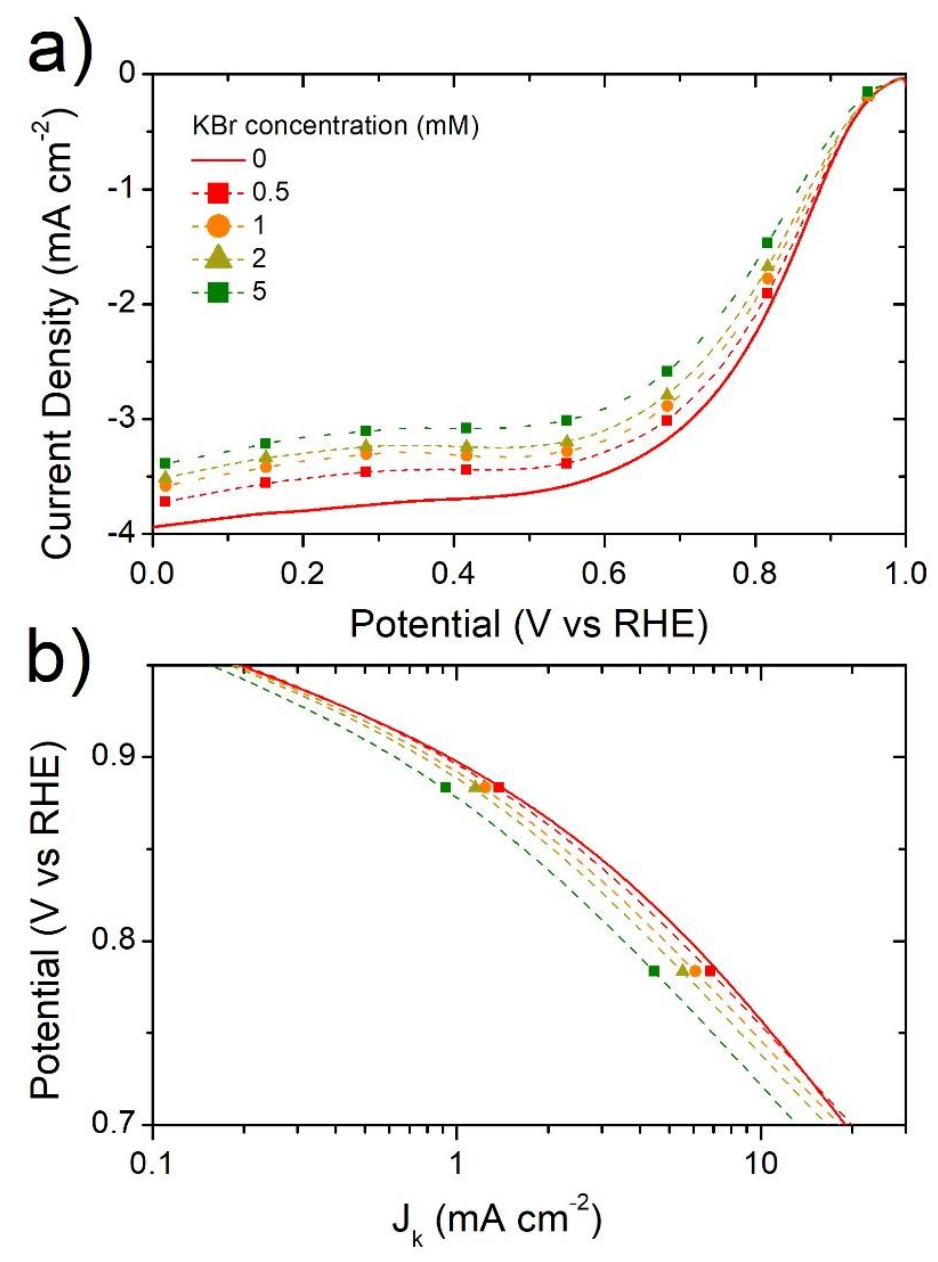

Figure 3. Effect of $\mathrm{KBr}$ concentration on the ORR polarisation curves of $\mathrm{Fe}_{0.5}-950$ with $\mathrm{PPO}-$ TEA. a) Linear polarisation curves, b) Tafel plots after correction for diffusion limitation by Koutecky-Levich analysis. 0.1 M KOH electrolyte saturated with $\mathrm{O}_{2}, 1600 \mathrm{rpm}$, scan rate 1 $\mathrm{mV} \mathrm{s}^{-1}$, catalyst loading $200 \mu \mathrm{g} \mathrm{cm}^{-2}$. 


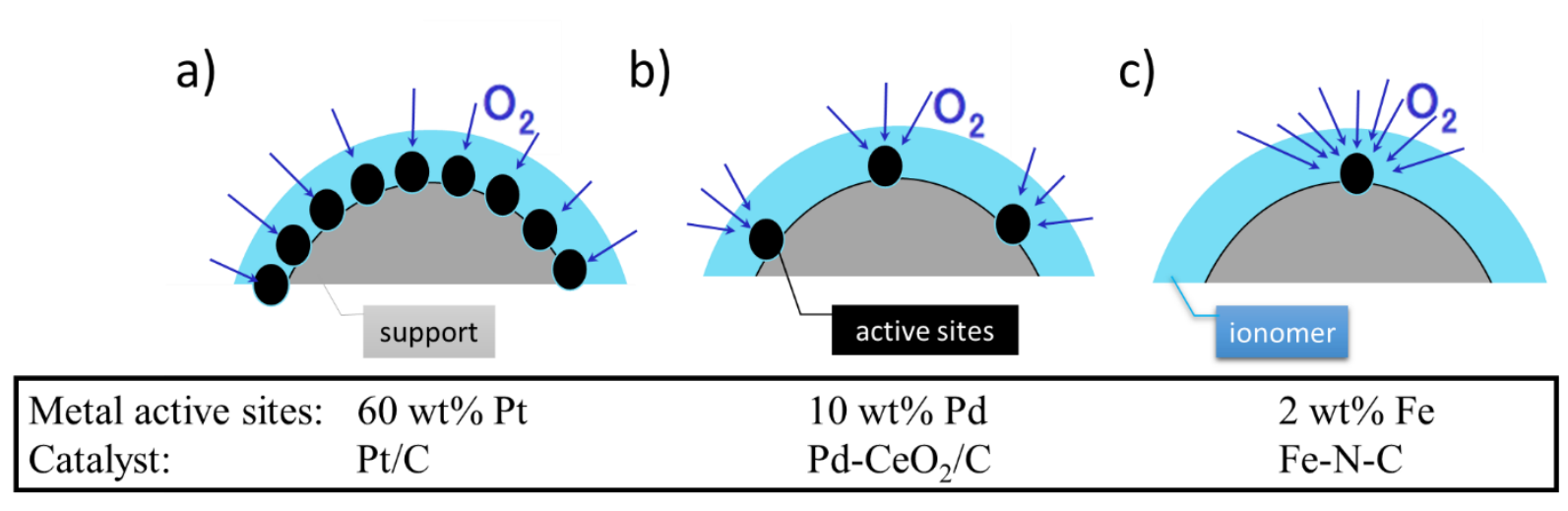

Figure 4. Scheme representing increasing $\mathrm{O}_{2}\left(\right.$ or $\left.\mathrm{H}_{2}\right)$ local flux with decreasing catalyst active site density, for a same total $\mathrm{O}_{2}\left(\right.$ or $\left.\mathrm{H}_{2}\right)$ consumption rate on one catalytic particle. 